of spinal degenerative MRI signs on X-rays (yes or no) and MRI (presence of Modic abnormalities, Pfirrmann score, Canal stenosis, Extrusion, High intensity zone Facet osteoarthritis) according to central reading (two readers) and axSpA diagnostic confidence (according to local clinician's confidence on a $0-10$ visual analog scale) were assessed by univariate analysis using the chi-square test (or Fisher's exact test where appropriate) and the Mann-Whitney test. Adjustment for multiple testing was performed according to Bonferroni method.

Results: Of 708 patients, data were available for 677,675 and 672 for SHA, LSA and TLA, measures with a mean value of $39.2^{\circ}, 14.5^{\circ}$ and $51.5^{\circ}$ respectively. Clinical features and diagnostic confidence did not differ between the SHA, LSA and TLA groups. More sacroilitis imaging, according to ASAS (41.4\% versus $32.0 \%)$ and MORPHO definition ( $48.6 \%$ versus $39.3 \%$ ), were reported in $\mathrm{TLA}<50^{\circ}$ group but the differences did not reach statistical significance. Radiological scores were low with a mean value of $0.49( \pm 1.83), 0.30( \pm 0.78)$ and $4.9( \pm 9.0)$ for mSASSS, BASRI-total and SPARCC score, respectively, and no inter-group difference was found. In L5S1, more grade 3 and 4 Pfirrmann class and MODIC discopathy (types 1 and 2) were observed for SHA $<40^{\circ}$, and TLA $<50^{\circ}(p<0.001)$ whereas the difference did not reach the significance level for $\operatorname{LSA}<15^{\circ}(\mathrm{p}=0.05)$ (table).

\begin{tabular}{|c|c|c|c|c|c|c|}
\hline \multirow{3}{*}{$\begin{array}{l}\text { Level } \\
\text { Angles }\end{array}$} & \multicolumn{6}{|c|}{ L5/S1 } \\
\hline & \multicolumn{2}{|c|}{ SHA } & \multicolumn{2}{|c|}{ LSA } & \multicolumn{2}{|c|}{ TLA } \\
\hline & $<40$ & $>40$ & $<15$ & $>15$ & $<50$ & $>50$ \\
\hline $\begin{array}{l}\text { Number of } \\
\text { patients }\end{array}$ & 328 & 300 & 313 & 313 & 270 & 353 \\
\hline $\begin{array}{l}\text { Pfirmann } \\
\text { class =3 }\end{array}$ & $\begin{array}{c}99 \\
(30.2)\end{array}$ & $\begin{array}{c}53 \\
(17.7) \\
* \star\end{array}$ & $\begin{array}{c}92 \\
(29.3)\end{array}$ & $\begin{array}{c}58 \\
(18.5)^{*}\end{array}$ & $\begin{array}{c}83 \\
(30.7)\end{array}$ & $\begin{array}{c}68 \\
(19.3) \\
* *\end{array}$ \\
\hline $\begin{array}{l}\text { High } \\
\text { Intensity } \\
\text { Zone }\end{array}$ & $\begin{array}{c}61 \\
(18.6)\end{array}$ & $\begin{array}{c}35 \\
(11.7)^{*}\end{array}$ & $\begin{array}{c}60 \\
(19.2)\end{array}$ & $\begin{array}{c}36 \\
(11.5)^{*}\end{array}$ & $\begin{array}{c}40 \\
(14.8)\end{array}$ & $\begin{array}{c}56 \\
(15.9)\end{array}$ \\
\hline $\begin{array}{l}\text { Disc } \\
\text { protr usion }\end{array}$ & $\begin{array}{c}37 \\
(11.3)\end{array}$ & $\begin{array}{c}22 \\
(7.3)\end{array}$ & $\begin{array}{c}27 \\
(8.6)\end{array}$ & $\begin{array}{c}30 \\
(9.6)\end{array}$ & $\begin{array}{c}34 \\
(12.6)\end{array}$ & $\begin{array}{c}24 \\
(6.8)^{*}\end{array}$ \\
\hline $\begin{array}{l}\text { Disc } \\
\text { extrusion }\end{array}$ & $\begin{array}{c}29 \\
(8.8)\end{array}$ & $\begin{array}{c}17 \\
(5.7)\end{array}$ & $\begin{array}{c}28 \\
(8.9)\end{array}$ & $\begin{array}{c}18 \\
(5.8)\end{array}$ & $\begin{array}{c}24 \\
(8.9)\end{array}$ & $\begin{array}{c}22 \\
(6.2)\end{array}$ \\
\hline $\begin{array}{l}\text { Canal } \\
\text { stenosis }\end{array}$ & $\begin{array}{c}8 \\
(2.4)\end{array}$ & $\begin{array}{c}2 \\
(0.7)\end{array}$ & $\begin{array}{c}2 \\
(0.7)\end{array}$ & $\begin{array}{c}7 \\
(2.2)\end{array}$ & $\begin{array}{c}7 \\
(2.6)\end{array}$ & $\begin{array}{c}3 \\
(0.8)\end{array}$ \\
\hline $\begin{array}{l}\text { MODIC } 1 \\
\text { signal }\end{array}$ & $\begin{array}{c}12 \\
(3.7)\end{array}$ & $\begin{array}{c}5 \\
(1.7)^{*}\end{array}$ & $\begin{array}{c}15 \\
(4.8)\end{array}$ & $\begin{array}{c}2 \\
(0.6)^{*}\end{array}$ & $\begin{array}{c}13 \\
(4.8)\end{array}$ & $\begin{array}{c}4 \\
(1.1)^{*}\end{array}$ \\
\hline $\begin{array}{l}\text { MODIC } 2 \\
\text { signal }\end{array}$ & $\begin{array}{c}7 \\
(2.1)\end{array}$ & $\begin{array}{c}1 \\
(0.3)^{*}\end{array}$ & $\begin{array}{c}2 \\
(0.6)\end{array}$ & $\begin{array}{c}1 \\
(0.3)^{*}\end{array}$ & $\begin{array}{c}5 \\
(1.8)\end{array}$ & $\begin{array}{c}3 \\
(0.4)^{*}\end{array}$ \\
\hline $\begin{array}{l}\text { Facet joint } \\
\text { osteoarthritis }\end{array}$ & $\begin{array}{c}1 \\
(0.3)\end{array}$ & $\begin{array}{c}2 \\
(0.7)\end{array}$ & $\begin{array}{c}1 \\
(0.3)\end{array}$ & $\begin{array}{c}2 \\
(0.6)\end{array}$ & $\begin{array}{c}1 \\
(0.4)\end{array}$ & $\begin{array}{c}2 \\
(0.6)\end{array}$ \\
\hline
\end{tabular}

Conclusions: Lumbar spine morphology is not associated with any clinical variable, presence on X-Rays or MRI of spinal signs of spondyloarthritis or sacroilitis. At the L5S1 level, a more horizontal SHA and a reduction of TLA is associated with more degenerative radiological lumbar spine manifestations.

Disclosure of Interest: None declared

DOI: 10.1136/annrheumdis-2017-eular.5128

\section{FRI0466 REAL-LIFE PERFORMANCE OF THE ASAS HEALTH INDEX IN ROUTINE CARE OF PATIENTS WITH SPONDYLOARTHRITIS}

U. Kiltz, T. Wiatr, X. Baraliakos, K. Fedorov, J. Braun. Rheumatology, Rheumazentrum Ruhrgebiet, Herne, Germany

Background: The measurement properties of the ASAS Health Index (ASAS HI) which has been developed to measure health and functioning of patients with spondyloarthritis $(\mathrm{SpA})$ have been evaluated in a cohort study. Its association with structural changes has not been examined to date.

Objectives: To investigate the relationship between clincial data, function and health as assessed by the ASAS HI in patients with axial SpA (axSpA) and to study the influence of structural spinal changes on this instrument.

Methods: Patients fullfilling ASAS classification criteria for axSpA were recruited prospectively. Information was collected on clinical assessments (ASAS $\mathrm{HI}$, NRS pain, BASDAI, ASDAS, BASFI, BASMI), laboratory parameters and spinal $x$-rays. Images were scored using mSASSS by two independent readers. The relationship between ASAS $\mathrm{HI}$ and other health outcomes was evaluated by Spearman correlation.

Results: A total of 150 patients ( $57 \mathrm{nr}$-axSpA and 93 AS patients) were included: $68.7 \%$ male, mean (SD) age 46.4 (14.1), symptom duration 18.7 (13.5) and diagnosis since 11.4 (11.8) years, and HLA-B27 positive in $82.0 \%$. Values of clinical assessments were ASAS HI 7.4 (4.1), BASDAI 4.7 (2.3), ASDAS 2.7 (1.1), BASMI 3.3 (1.8), pain 5.7 (2.7), and BASFI 4.7 (2.6). Elevated CRP levels were found in $34.8 \%$ of the patients. Radiographs of the sacroiliac (SI) joint and the spine were available in 138 patients, $38.0 \%$ of which had syndesmophytes and $7.5 \%$ had a bamboo spine. The median (IQR) mSASSS value was 4.3 (IQR 1.0-22.1) in AS und 0.2 (IQR 0.0-1.4) in nr-axSpA patients. Patients received a treatment with NSAIDs (62.7\%), DMARDs (20.9\%) and/or biologics $(49.4 \%)$. Significant correlation of ASAS HI was found for BASFI ( $r=0.8)$, BASDAI $(r=0.7)$, ASDAS ( $r=0.5)$ and BASMI $(r=0.5$, and, all $p<0.05)$. No correlations were found for ASAS HI and radiographic damage (mSASSS $r=0.2$, occurrence of syndesmophytes $r=0.01$, occurrence of bamboo spine $r=0.2$ ) and CRP levels $(r=0.07)$. Stratifying patients by symptom duration (cut-off 3 years) did not affect these results.

Conclusions: Established measures of function and spinal mobility correlate well with the ASAS $\mathrm{HI}$ in patients with axSpA. The influence of structural changes as measured by mSASSS on the ASAS HI was limited in this study, probably due to relatively low mSASSS scores at baseline.. Further study in more and more severe patients is needed to study the association of physical activity, spinal mobility, function and radiographic damage in axSpA.

Disclosure of Interest: None declared

DOI: 10.1136/annrheumdis-2017-eular.2202

\section{FRI0467 DEVELOPMENT AND PRELIMINARY VALIDATION OF THE COMPUTED TOMOGRAPHY SACROILIAC STRUCTURAL SCORE (CT-SSS) FOR ASSESSMENT OF STRUCTURAL LESIONS IN AXIAL SPONDYLOARTHRITIS}

W.P. Maksymowych ${ }^{1,2}$, M. Raynal $^{3}$, D. Loeuille ${ }^{3}$, M.-A. D'Agostino ${ }^{4}$, J. Paschke ${ }^{2}$, R.G. Lambert ${ }^{5} .{ }^{1}$ Medicine, University of Alberta; ${ }^{2}$ CaRE Arthritis, Edmonton, Canada; ${ }^{3}$ Rheumatology, CHRU de Nancy, Vandœuvre-lès-Nancy; ${ }^{4}$ Rheumatology, Université Paris Ouest, Paris, France; ${ }^{5}$ Radiology, University of Alberta, Edmonton, Canada

Background: Computed tomography (CT) is considered the imaging benchmark for the assessment of certain structural lesions in the sacroiliac joints (SIJ) of patients with axial spondyloarthritis (axSpA). Availability of low dose radiation techniques may lead to more widespread use, potentially as a structural endpoint in clinical trials research.

Objectives: We aimed to validate a new CT-based scoring method, the CT Sacroiliac Structural Score (CT-SSS), for assessing structural lesions in the SIJ. Methods: CT scans of the SIJ from 44 patients (26 females, mean age 49.4 years, mean symptom duration 9.1 years) were reconstructed in the semicoronal plane parallel to the superior border of the sacrum and scoring of lesions was confined to this plane. Structural lesions were scored in consecutive slices in SIJ quadrants (erosion, sclerosis) or SIJ halves (ankylosis) on a dichotomous basis (present/absent) using the same anatomical principles as developed for the SPARCC MRI SIJ inflammation and structural scores. The most anterior slice is defined as visible joint $\geq 1 \mathrm{~cm}$ vertical height and when $<3 \mathrm{~cm}$ is defined as having only upper iliac and sacral quadrants. A visible joint $>3 \mathrm{~cm}$ vertical height is defined as having 4 quadrants. At the posterior aspect of the SIJ, there is a natural separation of iliac and sacral cortical bone by structures in the ligamentary portion. Scoring is terminated when $<1 \mathrm{~cm}$ of iliac and sacral bone is appositional. Two readers independently scored CT scans without a prior calibration exercise and using direct online data entry onto a schematic of the SIJ. Reliability was assessed by kappa statistics, intra-class correlation coefficient (ICC), and Bland-Altman limits of agreement.

Results: Scoring was feasible (5-10 minutes per scan) and both ankylosis (ICC $=0.95)$ and erosion $(\mathrm{ICC}=0.81)$ were reliably scored (Table). Sclerosis was less reliably scored $(\mathrm{ICC}=0.39$ ). Presence/absence of ankylosis was reliably detected irrespective of whether this was based on a single slice $(\kappa=0.77)$ or 3 consecutive slices $(\kappa=0.81)$. Reliable detection was lower for erosion $(\kappa=0.50$ for 1 or 3 slices) and sclerosis ( $\kappa=0.44$ and 0.48 for 1 and 3 slices, respectively). Bland-Altman graphs illustrate reliability across the range of scores for ankylosis and erosion.

Table 1. Descriptive and Reliability data for CT-SSS score

\begin{tabular}{|c|c|c|c|c|c|c|}
\hline & \multicolumn{2}{|c|}{ Mean (SD) score } & \multicolumn{2}{|c|}{ Median (IQR) score } & \multirow[t]{2}{*}{ ICC } & \multirow[t]{2}{*}{$95 \% L$ of $A$} \\
\hline & $\mathrm{R} 1$ & $\mathrm{R} 2$ & $\mathrm{R} 1$ & $\mathrm{R} 2$ & & \\
\hline Erosion & $4.4(9.7)$ & $6.5(11.5)$ & $0(25.5)$ & $0(21)$ & 0.95 & $-10.7,13.5$ \\
\hline Ankylosis & $7.5(14.1)$ & $6(13.6)$ & 0 (12) & $0(12)$ & 0.81 & $-16.2,12.2$ \\
\hline Sclerosis & $6.6(14.4)$ & $7.4(18.2)$ & $0(20)$ & $0(24.5)$ & 0.39 & $-34.5,33.0$ \\
\hline
\end{tabular}

IQR interquartile range $\mathrm{L}$ of A Limits of Agreement.

Conclusions: The CT-SSS method is feasible and reliable for scoring ankylosis and erosion with minimal calibration. Sclerosis requires further standardization and calibration.

Disclosure of Interest: None declared

DOI: 10.1136/annrheumdis-2017-eular.5254

\section{FRI0468 RADIOGRAPHIC HIP INVOLVEMENT IN PATIENTS WITH ANKYLOSING SPONDYLITIS. A STUDY OF ITS PREVALENCE AND DETERMINING FACTORS}

X. Michelena, M. López de Recalde, H. Borrell, J. Lluch, P. Juárez, I. Morales, M. Pascual, J.-M. Nolla, X. Juanola. Department of Rheumatology, Hospital Universitari de Bellvitge, L'Hospitalet de Llobregat, Barcelona, Spain

Background: Hip involvement in Ankylosing Spondylitis (AS) is the most frequent extraspinal manifestation and a common cause of disability and limited mobility, often ending with hip replacement. There are few studies analysing the radiographic changes of the hip and their relationship with other disease variables. 